\title{
Assessment of Iron Deposition in the Brain in Frontotemporal Dementia and Its Correlation with Behavioral Traits
}

\author{
(D) R. Sheelakumari, (D). Kesavadas, (D). Varghese, (D).M. Sreedharan, (D) B. Thomas, (D). Verghese, and (DP.S. Mathuranath
}

\begin{abstract}
BACKGROUND AND PURPOSE: Brain iron deposition has been implicated as a major culprit in the pathophysiology of neurodegeneration. However, the quantitative assessment of iron in behavioral variant frontotemporal dementia and primary progressive aphasia brains has not been performed, to our knowledge. The aim of our study was to investigate the characteristic iron levels in the frontotemporal dementia subtypes using susceptibility-weighted imaging and report its association with behavioral profiles.
\end{abstract}

MATERIALS AND METHODS: This prospective study included 46 patients with frontotemporal dementia (34 with behavioral variant frontotemporal dementia and 12 with primary progressive aphasia) and 34 age-matched healthy controls. We performed behavioral and neuropsychological assessment in all the subjects. The quantitative iron load was determined on SWI in the superior frontal gyrus and temporal pole, precentral gyrus, basal ganglia, anterior cingulate, frontal white matter, head and body of the hippocampus, red nucleus, substantia nigra, insula, and dentate nucleus. A linear regression analysis was performed to correlate iron content and behavioral scores in patients.

RESULTS: The iron content of the bilateral superior frontal and temporal gyri, anterior cingulate, putamen, right hemispheric precentral gyrus, insula, hippocampus, and red nucleus was higher in patients with behavioral variant frontotemporal dementia than in controls. Patients with primary progressive aphasia had increased iron levels in the left superior temporal gyrus. In addition, right superior frontal gyrus iron deposition discriminated behavioral variant frontotemporal dementia from primary progressive aphasia. A strong positive association was found between apathy and iron content in the superior frontal gyrus and disinhibition and iron content in the putamen.

CONCLUSIONS: Quantitative assessment of iron deposition with SWI may serve as a new biomarker in the diagnostic work-up of frontotemporal dementia and help distinguish frontotemporal dementia subtypes.

ABBREVIATIONS: $\mathrm{ACE}=$ Addenbrooke's Cognitive Examination; $\mathrm{AD}=$ Alzheimer disease; $\mathrm{ALS}=$ amyotrophic lateral sclerosis; bvFTD = behavioral variant frontotemporal dementia; FrSBe = Frontal System Behavioral Scale; FTD = frontotemporal dementia; PPA = primary progressive aphasia

$F^{\prime}$ ontotemporal dementia (FTD) is an early-onset dementia characterized by changes in behavior, personality, and language abilities. The major clinical presentations are frontal or behavioral variant FTD (bvFTD) with personality and behavioral changes, and the language variant known as primary progressive

Received January 27, 2017; accepted after revision June 5.

From the Cognition and Behavioural Neurology Section, Department of Neurology (R.S., T.V., P.S.M.) and Department of Imaging Sciences and Interventional Radiology (C.K., B.T.), Sree Chitra Tirunal Institute for Medical Sciences and Technology, Trivandrum, Kerala, India; Department of Radiodiagnostics (R.M.S.), Medical College, Trivandrum, Kerala, India; Integrated Divisions of Cognitive and Motor Aging (Neurology) and Geriatrics (Medicine) (J.V.), Albert Einstein College of Medicine, Bronx, New York; and Department of Neurology (P.S.M.), National Institute of Mental Health and Neurosciences, Banglore, Karnataka, India.

This study was supported by grants from National Institute on Aging (grant No. R21AG029799 and R01AG039330-01) to P.S.M.

Please address correspondence to P.S. Mathuranath, MD, National Institute of Mental Health and Neurosciences, Hosur Rd, Banglore, Karnataka, India 560029; e-mail: psmathu@yahoo.com aphasia (PPA), with either prominent isolated expressive language deficits, progressive nonfluent aphasia, or prominent language comprehension and semantic deficits, semantic dementia. ${ }^{1}$ Because standard neuropsychological testing often fails to detect the disease in its early stages and the behavioral changes predate neuropsychological deficits, ${ }^{2}$ a major clinical challenge is to develop a biomarker for the early and accurate diagnosis of FTD.

Several neurodegenerative disorders such as Alzheimer disease (AD), ${ }^{3}$ Parkinson disease, ${ }^{4}$ multiple sclerosis, ${ }^{5}$ amyotrophic lateral sclerosis (ALS), ${ }^{6,7}$ neuroferrinopathy, panthothenate-kinase2-associated neurodegeneration, and aceruloplasminemia ${ }^{8}$ have been found to be associated with excessive iron accumulation. Also, our previous study in ALS demonstrated abnormal brain

\footnotetext{
- Indicates open access to non-subscribers at www.ajnr.org

I. Indicates article with supplemental on-line photo.

http://dx.doi.org/10.3174/ajnr.A5339
}

AJNR Am J Neuroradiol 38:1953-58 Oct 2017 www.ajnr.org 
iron deposition in the posterior bank of the motor cortex, and this could be a potential biomarker for ALS. ${ }^{9}$ Recently, there has been an increasing interest concerning in vivo quantitative estimation of nonheme iron in the pathophysiology of AD. ${ }^{10,11}$ Postmortem studies have indicated neurodegeneration with brain iron deposition in FTD-ALS ${ }^{12}$ and Pick disease. ${ }^{13}$ A recent study in postmortem brains suggested that iron-impaired homeostasis possibly plays a crucial role in the pathogenesis of frontotemporal lobar degeneration. ${ }^{14}$

The neuropathologic basis of neurodegeneration in frontotemporal lobar degeneration is highly linked to different proteinopathies such as TAR DNA-binding protein 43 and fused in sarcoma proteins, ${ }^{25,26}$ which have been found to be responsible for the focal atrophy in frontotemporal and subcortical areas. ${ }^{17}$ De Reuck et $\mathrm{al}^{14}$ found a significantly higher iron load in fused in sarcoma and TAR DNA-binding protein subgroups than in those with $\tau$-frontotemporal lobar degeneration. Although it is widely accepted that the excessive iron accumulation contributes to neurodegeneration, it is not yet clear whether this is a primary or secondary event of the disease process. Iron is an important element for normal brain function due to its critical role in oxidative metabolism, DNA synthesis, and other enzymatic cellular processes. The metabolism of iron depends on the human hemochromatosis protein located on the cell membrane, which regulates uptake of iron by modulating the binding affinity of the transferrin receptor for iron-loaded transferrin. ${ }^{18}$ Also the line of evidence indicates that the genetic variant of human hemochromatosis protein, namely H63D polymorphism in frontotemporal lobar degeneration, can foster the increased iron deposition in the basal ganglia regions. ${ }^{19}$ In light of these new findings, the search for a biomarker capable of detecting cell death in anatomically specific patterns could be useful, similar to FDG-PET imaging in dementia, but at a lower cost and without any ionizing radiation exposure.

In recent years, susceptibility-weighted imaging has been confirmed as a tool to quantify iron deposition in the brain, which exploits magnetic susceptibility differences among tissues. ${ }^{20,21}$ SWI is a $3 \mathrm{D}$ gradient technique that uses both magnitude and phase data, separately and together, to enhance the susceptibility differences among tissues. SWI has been shown to be more sensitive to nonheme iron (ferritin) than other conventional techniques. $^{22}$ The present study was conducted to unravel the regional changes in the iron concentration in the brains of patients with FTD. This in vivo measurement could potentially offer a good diagnostic tool for identifying the disease and studying the underlying pathophysiologic mechanisms. The goal of the present study was to quantify iron deposition in bvFTD and PPA in comparison with age-matched controls using SWI and to correlate these findings with behavioral test measures.

\section{MATERIALS AND METHODS Subjects}

A total of 46 patients with FTD (34 with bvFTD, 12 with PPA [7 with semantic dementia and 5 with progressive nonfluent aphasia]) and 34 controls were included in the study after we obtained signed informed consent from the participants and their caregivers. The study had approval from the institutional ethics commit- tee. The patients were recruited from the Memory and Neurobehavioral Clinic at Sree Chitra Tirunal Institute for Medical Sciences and Technology, a tertiary referral center in Trivandrum City, Kerala, India. The initial clinical diagnosis of FTD was established by an experienced cognitive neurologist (P.S.M.) as per the published FTD consensus criteria ${ }^{1}$ and was subsequently confirmed by neuropsychological and neuroimaging examinations. All the patients with bvFTD met the recently published criteria by Rascovsky et $\mathrm{al}^{23}$ and those with PPA met Mesulam criteria. ${ }^{24}$ Further, the PPA variants were identified based on the guidelines of an international group of PPA investigators. ${ }^{25}$ We excluded patients with a history of cerebral ischemic infarction or hemorrhage, head trauma, alcohol abuse, cardiovascular and major psychiatric diseases, or a history of depressive illness and epilepsy or other neurologic disorders. The age-matched controls with no history of major neurologic or psychiatric illnesses and no contraindications for MR imaging were recruited from the local community and subjected to the same assessment as for FTD.

The cognitive assessment was performed with a neuropsychological battery that was validated for the local elderly population as described previously. ${ }^{26}$ The test battery included the brief cognitive test of the Mini-Mental State Examination and the detailed global cognitive test of the Addenbrooke's Cognitive Examination (ACE). Furthermore, patients underwent a behavioral assessment test with the Frontal System Behavioral Scale (FrSBe), which investigates behaviors associated with frontal system damage such as apathy, disinhibition, and executive dysfunction.

\section{Image Acquisition}

All images were acquired on a 1.5T whole-body scanner (Avanto; Siemens, Erlangen, Germany) equipped with an 8-channel phased array head coil. In all subjects, sagittal T1-weighted images were acquired to locate the prescribed positions of the anterior/ posterior commissures. Conventional T1-weighted and T2weighted images were acquired with MR imaging sections aligned parallel to the anterior/posterior commissure line to screen the subjects for other cerebral anatomic abnormalities such as traumatic brain injury, old hemorrhagic infarcts, and so forth. SWI imaging was performed with a 3D spoiled gradient recalled-echo sequence with the following parameters: TR/TE, 49/40 ms; flip angle, $20^{\circ}$; section thickness, $2.1 \mathrm{~mm}$; number of sections, 56; FOV , $250 \times 203 \mathrm{~mm}$; matrix size, $260 \times 320$. For the analysis, the images were high-pass-filtered with a low spatial frequency kernel and a central matrix size of $64 \times 64$. The resulting image is the SWI filtered phase image. The filtered phase image served as an indicator of phase variations and hence the concentration of iron. The details of the measurement of iron in the order of micrograms of iron/gram of tissue are described elsewhere. ${ }^{9,20,21}$ The 3D FLASH volumetric scans were also acquired for the anatomic localization based on surface landmarks.

\section{Image Analysis}

All the susceptibility-weighted images were examined by 2 certified and experienced neuroradiologists (C.K.) and (B.T.). The high-pass-filtered images were analyzed with signal processing in nuclear MR software (SPIN; MR Imaging Institute for Biomedical Research, Detroit, Michigan). Both the SWI and phase images 
Table 1: Demographic, clinical, and behavioral data comparison ${ }^{a}$

\begin{tabular}{|c|c|c|c|c|}
\hline & Controls & bvFTD & PPA & $\begin{array}{c}P \text { Value } \\
\text { (Group Effect) }\end{array}$ \\
\hline Age $(y r)^{b}$ & $61.07 \pm 6.15$ & $61.18 \pm 11.96$ & $64.64 \pm 3.98$ & .55 \\
\hline Sex & $18 / 16$ & $23 / 11$ & $8 / 4$ & .33 \\
\hline \multicolumn{5}{|l|}{$\mathrm{FrSBe}$} \\
\hline Apathy & $19.36 \pm 10.55$ & $30.26 \pm 11.72$ & $27.58 \pm 13.16$ & .003 \\
\hline Disinhibition & $15.86 \pm 2.12$ & $33.74 \pm 9.27$ & $24 \pm 8.07$ & $<.001$ \\
\hline Executive dysfunction & $20.41 \pm 5.68$ & $56.65 \pm 16.93$ & $34 \pm 9.73$ & $<.001$ \\
\hline \multicolumn{5}{|c|}{ Neuropsychological test scores } \\
\hline MMSE & $28.66 \pm 1.11$ & $18.9 \pm 7.71$ & $22.82 \pm 5.51$ & $<.001$ \\
\hline $\mathrm{ACE}$ & $92.45 \pm 7.03$ & $53.29 \pm 24.9$ & $55.9 \pm 20.59$ & $<.001$ \\
\hline
\end{tabular}

${ }^{a}$ Bonferroni post hoc tests compare differences between groups; both MMSE and ACE scores were absent in 8 patients with bvFTD and 2 with PPA.

b Student $t$ test

${ }^{c} \chi^{2}$ test.

Table 2: Iron content (micrograms of iron/gram of tissue) of each region in bvFTD, PPA, and the control group

\begin{tabular}{|c|c|c|c|c|c|c|}
\hline \multirow[b]{2}{*}{ Region } & \multirow[b]{2}{*}{ Controls } & \multirow[b]{2}{*}{ bvFTD } & \multirow[b]{2}{*}{ PPA } & \multicolumn{3}{|c|}{ Bonferroni-Corrected $P$ Value ${ }^{a}$} \\
\hline & & & & $\begin{array}{l}\text { bvFTD vs } \\
\text { Controls }\end{array}$ & $\begin{array}{l}\text { PPA vs } \\
\text { Controls }\end{array}$ & $\begin{array}{c}\text { bvFTD vs } \\
\text { PPA }\end{array}$ \\
\hline LSFG & $13.17 \pm 5.78$ & $24.35 \pm 10.02$ & $18.61 \pm 4.23$ & $<.001^{\mathrm{b}}$ & .123 & .09 \\
\hline RSFG & $12.55 \pm 5.51$ & $25.36 \pm 9.82$ & $18.45 \pm 5.11$ & $<.001^{\mathrm{b}}$ & .75 & $.03^{\mathrm{b}}$ \\
\hline LPCG & $35.16 \pm 10.03$ & $40.17 \pm 7.39$ & $37.14 \pm 8.28$ & .064 & 1.00 & .914 \\
\hline RPCG & $33.46 \pm 14.29$ & $41.74 \pm 7.1$ & $39.2 \pm 12.11$ & $.012^{\mathrm{b}}$ & .416 & 1.00 \\
\hline LAC & $17.21 \pm 7.71$ & $21.31 \pm 5.72$ & $18.57 \pm 4.21$ & $.034^{\mathrm{b}}$ & 1.00 & .634 \\
\hline RAC & $16.72 \pm 5.7$ & $22.15 \pm 6.1$ & $17.97 \pm 3.79$ & $.001^{\mathrm{b}}$ & 1.00 & .092 \\
\hline LIN & $12.44 \pm 5.4$ & $15.91 \pm 7.09$ & $15.33 \pm 5.33$ & .074 & .512 & 1.00 \\
\hline RIN & $11.86 \pm 5.59$ & $16.55 \pm 7.83$ & $14.14 \pm 2.78$ & $.01^{\mathrm{b}}$ & .883 & .793 \\
\hline LCAU & $25.76 \pm 12.05$ & $29.00 \pm 12.46$ & $27.19 \pm 4.88$ & .756 & 1.00 & 1.00 \\
\hline RCAU & $24.96 \pm 13.46$ & $31.43 \pm 13.79$ & $25.87 \pm 7.32$ & .13 & 1.00 & .609 \\
\hline LPUT & $20.96 \pm 11.23$ & $26.98 \pm 8.95$ & $21.18 \pm 5.33$ & $.037^{\mathrm{b}}$ & 1.00 & .227 \\
\hline RPUT & $20.61 \pm 9.5$ & $27.84 \pm 8.12$ & $21.13 \pm 6.49$ & $.003^{b}$ & .06 & .066 \\
\hline LGP & $27.58 \pm 10.25$ & $30.66 \pm 9.08$ & $28.39 \pm 7.58$ & .55 & 1.00 & 1.00 \\
\hline RGP & $26.65 \pm 7.27$ & $32.3 \pm 11.51$ & $28.11 \pm 8.68$ & .053 & 1.00 & .585 \\
\hline LFWM & $13.96 \pm 6.61$ & $14.67 \pm 5.91$ & $15.21 \pm 3.17$ & 1.00 & 1.00 & 1.00 \\
\hline RFWM & $13.65 \pm 5.98$ & $17.08 \pm 6.77$ & $13.30 \pm 4.64$ & .078 & 1.00 & .217 \\
\hline LHP & $12.28 \pm 7.60$ & $15.64 \pm 7.07$ & $15.58 \pm 4.09$ & .156 & .493 & 1.000 \\
\hline RHP & $11.95 \pm 6.6$ & $17.01 \pm 8.82$ & $14.89 \pm 4.21$ & $.024^{\mathrm{b}}$ & .671 & 1.00 \\
\hline LTP & $13.72 \pm 5.44$ & $21.90 \pm 8.69$ & $19.67 \pm 5.16$ & $<.001^{\mathrm{b}}$ & $.041^{\mathrm{b}}$ & 1.00 \\
\hline RTP & $13.25 \pm 5.9$ & $23.41 \pm 8.71$ & $18.77 \pm 4.35$ & $<.001^{\mathrm{b}}$ & .07 & .166 \\
\hline LRN & $27.29 \pm 11.07$ & $30.39 \pm 10.99$ & $27.90 \pm 7.99$ & .709 & 1.00 & 1.00 \\
\hline RRN & $24.21 \pm 9.13$ & $31.58 \pm 12.66$ & $24.69 \pm 9.05$ & $.02^{b}$ & 1.00 & .177 \\
\hline LSN & $26.78 \pm 11.63$ & $30.90 \pm 9.90$ & $28.05 \pm 10.64$ & .365 & 1.00 & 1.00 \\
\hline RSN & $26.64 \pm 12.49$ & $31.0 \pm 11.25$ & $27.85 \pm 11.09$ & .403 & 1.00 & 1.00 \\
\hline LDN & $20.71 \pm 8.84$ & $23.26 \pm 7.86$ & $21.41 \pm 7.47$ & .633 & 1.00 & 1.00 \\
\hline RDN & $19.93 \pm 6.5$ & $24.03 \pm 8.41$ & $20.47 \pm 3.96$ & .064 & 1.00 & .424 \\
\hline
\end{tabular}

Note:-RTP indicates right temporal pole; LTP, left temporal pole; LIN, left insula; RIN, right insula; LCAU, left caudate; RCAU, right caudate; RPUT, right putamen; LPUT, left putamen; LGP, left globus pallidus; RGP, right globus pallidus; LFWM, left frontal white matter; RFWM, right frontal white matter; LHP, left head and body of the hippocampus; RHP, right head and body of the hippocampus; LRN, left red nucleus; RRN, right red nucleus; RSN, right substantia nigra; LSN, left substantia nigra; RSFG, right superior frontal gyrus; LSFG, left superior frontal gyrus; LDN, left dentate nucleus; RDN, right dentate nucleus; RPCG, right precentral gyrus just anterior to central sulcus; LPCG, left precentral gyrus just anterior to central sulcus; LAC, left gray matter abutting and posterior to the cingulate sulcus along with adjacent medial frontal lobe; RAC, right gray matter abutting and posterior to the cingulate sulcus along with adjacent medial frontal lobe.

a Bonferroni post hoc tests compare differences among groups.

b Significant.

were used for the analysis. Initially, the brightness and contrast of the images were adjusted and magnified 2 times to obtain the anatomic landmark of each structure. Second, ROIs were determined and drawn manually on respective SWI sections with extreme care to minimize partial volume effects. The regions were selected on the basis of known functions of different parts of the brain and the published structural MR imaging studies that had objectives comparable with those in our study. Many of these studies have described significant GM volume loss in the frontal, insular, anterior cingulate, caudate, putaminal, thalamic, and temporal polar regions in bvFTD ${ }^{27-29}$ and predominant temporal (temporal pole, anterior hippocampus) and extratemporal (ventromedial prefrontal cortex, insula, anterior cingulate, caudate) regions in PPA. ${ }^{28,30,31}$ Hence, the ROIs were drawn on both hemispheres with the help of e-anatomy of IMAIOS (https://www.imaios.com/en/e-Anatomy/ Head-and-Neck/Brain-MRI-3D) and included the following: the GM at the precentral gyrus just anterior to central sulcus, adjacent subcortical WM and CSF in the central sulcus, the superior frontal gyrus medial to superior frontal sulcus, temporal pole, insula, basal ganglia regions (caudate), putamen, globus pallidus, substantia nigra, red nucleus, frontal WM, anterior cingulate defined by the gray matter abutting and posterior to the cingulate sulcus along with adjacent medial frontal lobe, hippocampus including its head and body, and, finally, the dentate nucleus (On-line Figure). Inferior and middle frontotemporal regions were avoided in the analysis specifically to reduce the contribution of susceptibility artifacts of the skull base. Finally, each ROI was copied to phase images for measuring the mean phase values. To ensure the consistency in measurement, phase values were measured independently by 2 observers (R.S. and R.M.S.).

To compare data across patients, we assumed that the CSF in each patient contained zero iron. ${ }^{32}$ Hence, the iron content in an ROI was directly proportional to the shift in phase between the CSF and the particular ROI.

\section{Statistical Analysis}

Statistical analysis was performed with the Statistical Package for the Social Sciences 20.0 (IBM, Armonk, New York). The age and sex distribution among subjects was compared with the Student $t$ test and $\chi^{2}$ test, respectively. The interrater agreement between the 2 observers on iron measurement was calculated with $\kappa$ statistics. The comparison among the mean values of neuropsychological scores, behavioral scores, and iron in each ROI between groups was performed by 1-way ANOVA analysis with a post hoc Bonferroni procedure. 
All statistical tests were set at a significance of $P<.05$. Finally, a linear regression analysis was performed to assess the correlation between iron content and behavioral scores.

\section{RESULTS}

\section{Subject Characteristics}

The demographic, neuropsychological, and behavioral data are summarized in Table 1 . The patients and controls were comparable on age $(P=.5)$, and sex $(P=.33)$. The patients with bvFTD were significantly worse than those with PPA on FrSBe scores of apathy, disinhibition, and executive dysfunction. Furthermore, those with bvFTD and PPA demonstrated pathologic scores on the ACE and MMSE compared with controls. The direct comparison between patient groups revealed significantly greater behavioral scores of disinhibition and executive dysfunction in bvFTD compared with PPA.

\section{Quantitative Measurement of Brain Iron Content in a Patient with FTD}

We observed a very good interrater agreement $(\kappa=0.88)$ between the 2 raters in the quantitative measurement of iron values.

The quantitative assessment of brain iron deposition (micrograms of iron/gram of tissue) in the various regions in patients with FTD demonstrated significantly increased iron levels in bi-

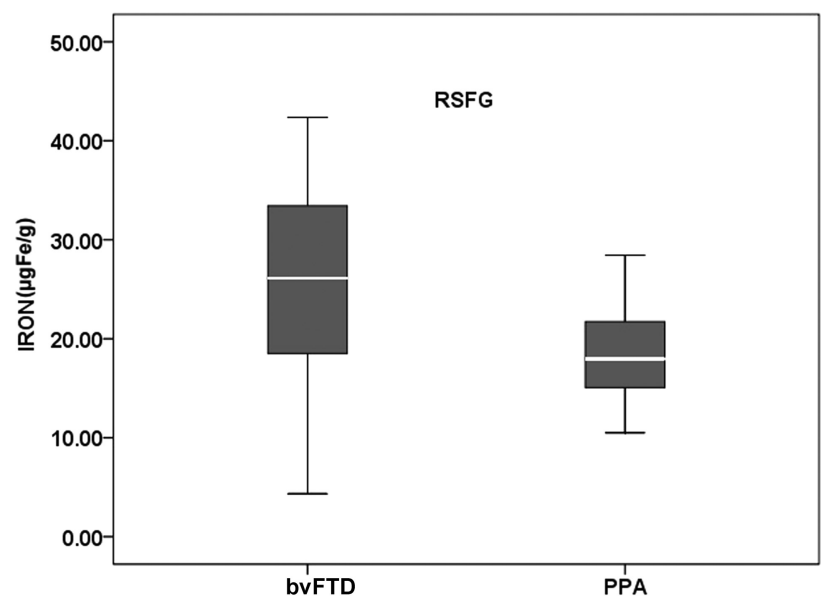

FIG 1. Boxplot showing iron content in the superior frontal gyrus in the direct comparison among patient groups. RSFG indicates right superior frontal gyrus.

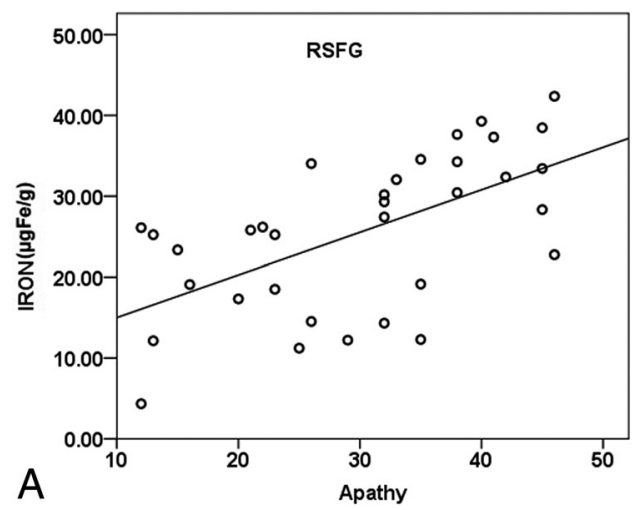

lateral superior frontal gyrus $(P<.001)$, bilateral temporal pole $(P<.001)$, bilateral anterior cingulate $(P=.001$ for the right and $P=.034$ for the left), bilateral putamen $(P=.003$ for the right and $P=.037$ for the left), right precentral gyrus just anterior to central sulcus $(P=.012)$, right insula $(P=.01)$, right hippocampus $(P=$ $.024)$, and right red nucleus $(P=.02)$ in patients with bvFTD compared with controls (Table 2).

In patients with PPA, a significant iron level was noted in the left temporal pole $(P=.041)$ and a trend toward significance in the right temporal pole $(P=.073)$. A direct comparison between those with bvFTD and PPA showed an increased iron deposition in the right superior frontal gyrus $(P=.03)$ in those with bvFTD (Fig 1).

\section{Relationship between Cortical Brain Iron Deposition and Behavioral Scores}

Linear regression analysis examining the relationship between cortical iron deposition and FrSBe subscores found a significant positive association between the iron content in the right superior frontal gyrus and apathy scores $\left(r^{2}=0.36, P<.001\right)$ and the right putamen and disinhibition scores $\left(r^{2}=0.25, P=.003\right)$ (Fig 2). No association was found between the iron content of any of the examined regions and executive dysfunction scores. The patients with PPA did not show any correlation with iron content and any of the behavioral scores.

\section{DISCUSSION}

In this study, we quantified the extent of brain iron deposition in the cortical and subcortical regions of patients with FTD in comparison with controls and correlated this with behavioral measures. To our knowledge, no other previous studies have performed a quantitative in vivo assessment of brain iron deposition in patients with FTD.

Pathologic accumulation of brain iron is shown in various neurodegenerative diseases including $\mathrm{AD} .{ }^{33}$ A previous postmortem study with 7T MR imaging on the detection of microbleeds in FTD demonstrated an iron overload in the basal ganglia. ${ }^{34}$ The investigators also found a large number of microbleeds in the frontal cerebral cortex with gradient-echo $\mathrm{T} 2{ }^{*}$-weighted MR imaging sections. Also, a recent postmortem study confirmed the presence of iron in the deep gray nuclei in FTD brains. ${ }^{14}$ Activated microglial cells and iron are known to accumulate at the neuro-

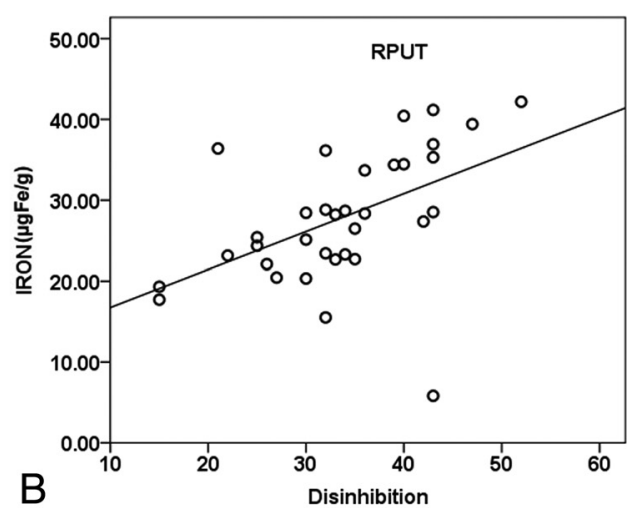

FIG 2. Correlation between iron concentration (micrograms of iron/gram of tissue) in the right superior frontal gyrus (RSFG) (A) and apathy, and the right putamen (RPUT) (B) and disinhibition scores in patients with bvFTD. 
degenerative sites in $\mathrm{AD}$ and Parkinson disease. ${ }^{35}$ These microglial cells have been implicated in maintaining the iron homeostasis in the brain by scavenging excess iron. ${ }^{36}$ It has been reported that chronic microglial activation in FTD can cause the expression of progranulin and the production of proinflammatory mediators by phosphor- $\tau$-positive neurons, which may contribute to neuronal death and disease progression. ${ }^{37}$

Prior studies have proved the efficacy of SWI in the quantitative assessment of cerebral iron content in subjects with dementia. ${ }^{3,4,10}$ Wang et al ${ }^{10}$ identified increased iron content in the hippocampus, head of the caudate, lenticular nucleus, and thalamus in those with amnestic mild cognitive impairment and AD compared with controls. Further, Zhou et $\mathrm{al}^{3}$ demonstrated that SWI phase values of the bilateral hippocampus, globus pallidus, caudate, substantia nigra, and putamen were significantly different between those with $\mathrm{AD}$ and controls, which had a higher correlation coefficient with MMSE scores. Recently, Wu et al ${ }^{4}$ suggested that a quantitative assessment of iron in the substantia nigra and globus pallidus with SWI may be useful for the early diagnosis and evaluation of the degree of disease in Parkinson disease.

The strength of the present study is the quantitative assessment of brain iron deposition in the frontal, temporal, and basal ganglia regions in FTD subtypes in comparison with controls without dementia using SWI. We found significantly increased levels of iron in the bilateral superior frontal gyrus, temporal pole, anterior cingulate, and putamen along with the right hemispheric insula, precentral gyrus, hippocampus, and red nucleus in patients with bvFTD compared with controls. The patients with PPA only showed significant iron levels in the left temporal pole in comparison with controls. A direct comparison revealed significant iron deposition in the right superior frontal gyrus in patients with bvFTD.

Earlier studies proved significant GM and WM degeneration in the frontoinsular-striatial-temporal regions in bvFTD ${ }^{27,38,39}$ and more severe temporal atrophy in PPA. ${ }^{39,40}$ Recently, De Reuck et $\mathrm{al}^{14}$ analyzed the postmortem brains of patients with neurodegenerative and cerebrovascular disease and observed the most significant iron deposition in the claustrum, caudate, and putamen and comparatively lesser significant deposition in the globus pallidus, thalamus, and subthalamic nucleus in those with FTD compared with controls. These findings support our observation of increased iron deposition in the basal ganglia regions. Moreover, our volumetric results in the same patient group showed characteristic atrophy patterns in the basal ganglia (R.S. et al, unpublished data, 2016), which corroborate previous findings. ${ }^{41}$ Notably, a prior tractography analysis in the human brain demonstrated well-established connections within the frontostriatal networks. ${ }^{42}$ The significant iron deposition in the red nucleus of those with bvFTD may be due to its strong functional coherence with prefrontal, insular, temporal, parietal, thalamic, and hypothalamic regions. ${ }^{43}$ In fact, the amount of iron deposition in the superior frontal gyrus and putamen correlated with the behavioral manifestations, as measured by the FrSBe, which has been implicated in the behavioral studies in FTD. ${ }^{44,45}$ The role of the putamen in disinhibition may be due to its afferent connections to the medial, orbital, and dorsolateral prefrontal regions as well as its link with the prefrontal and motor circuits. ${ }^{46}$ Therefore the regional iron deposition, as measured by SWI, may be used as a novel biomarker in the diagnosis of FTD subtypes.

This study has some limitations. Our sample size in PPA was relatively small. Also, some of the subjects were unable to complete the neuropsychological tests due to a more advanced stage of the disease. Although our patient group had characteristic symptomatology and conformed to the diagnostic criteria, pathologic confirmation of FTD has not been established for all subjects. Hence, future longitudinal studies on larger samples with neuropathologic data and higher resolution scanners (3T or 7T) could help verify and consolidate our conclusions. Nevertheless, this study provides insight into an angle for pursuing the search for biomarkers in FTD.

\section{CONCLUSIONS}

The results of the study showed that SWI could be a potential biomarker for measuring iron deposition in the FTD brain and iron increases in the frontal and temporal regions of patients. The study also demonstrated a significant correlation between regional iron content and behavioral profiles.

Disclosures: R. Sheelakumari-RELATED: Grant: National Institute on Aging*. Tinu Varghese-RELATED: Grant: National Institute on Aging.* Bejoy ThomasUNRELATED: Grants/Grants Pending: GE Healthcare, Comments: Coinvestigator in an unrelated project*; Patents (Planned, Pending or Issued): Indian patent application filed.* Joe Verghese-RELATED: Grant: National Institutes of Health, Comments: Kerala-Einstein Study: Healthy Lifestyle, Vascular Disease, and Cognitive Decline; type, R01 AG039330-01; role, Principal Investigator; agency, National Institute on Aging, Fogarty Institute*. Pavagadha Mathuranath—RELATED: Grant: National Institute on Aging, Comments: grant Nos. R21AG029799 and R01AG039330-01 to P.S.M. * ${ }^{\star}$ Money paid to the institution.

\section{REFERENCES}

1. Neary D, Snowden JS, Gustafson L, et al. Frontotemporal lobar degeneration: a consensus on clinical diagnostic criteria. Neurology 1998;51:1546-54 CrossRef Medline

2. Perry RJ, Graham A, Williams G, et al. Patterns of frontal lobe atrophy in frontotemporal dementia: a volumetric MRI study. Dement Geriatr Cogn Disord 2006;22:278-87 CrossRef Medline

3. Zhou B, Li S, Huijin H, et al. The evaluation of iron content in Alzheimer's disease by magnetic resonance imaging: phase and $\mathrm{R} 2{ }^{*}$ methods. Adv Alzheimer Dis 2013;2:51-59 CrossRef

4. Wu SF, Zhu ZF, Kong Y, et al. Assessment of cerebral iron content in patients with Parkinson's disease by the susceptibility-weighted MRI. Eur Rev Med Pharmacol Sci 2014;18:2605-08 Medline

5. Ropele S, de Graaf W, Khalil M, et al. MRI assessment of iron deposition in multiple sclerosis. J Magn Reson Imaging 2011;34:13-21 CrossRef Medline

6. Adachi Y, Sato N, Saito Y, et al. Usefulness of SWI for the detection of iron in the motor cortex in amyotrophic lateral sclerosis. $\mathrm{J} \mathrm{Neu}$ roimaging 2015;25:443-51 CrossRef Medline

7. Kwan JY, Jeong SY, Van Gelderen P, et al. Iron accumulation in deep cortical layers accounts for MRI signal abnormalities in ALS: correlating 7 Tesla MRI and pathology. PLoS One 2012;7:e35241 CrossRef Medline

8. Batista-Nascimento L, Pimentel C, Menezes RA, et al. Iron and neurodegeneration: from cellular homeostasis to disease. Oxid Med Cell Longev 2012;2012:128647 CrossRef Medline

9. Sheelakumari R, Madhusoodanan M, Radhakrishnan A, et al. A potential biomarker in amyotrophic lateral sclerosis: can assessment of brain iron deposition with SWI and corticospinal tract degeneration with DTI help? AJNR Am J Neuroradiol 2016;37:252-58 CrossRef Medline

10. Wang D, Zhu D, Wei XE, et al. Using susceptibility-weighted images to quantify iron deposition differences in amnestic mild cognitive 
impairment and Alzheimer's disease. Neurol India 2013;61:26-34 CrossRef Medline

11. Raven EP, Lu PH, Tishler TA, et al. Increased iron levels and decreased tissue integrity in hippocampus of Alzheimer's disease detected in vivo with magnetic resonance imaging. J Alzheimers Dis 2013;37:127-36 CrossRef Medline

12. Santillo AF, Skoglund L, Lindau M, et al. Frontotemporal dementiaamyotrophic lateral sclerosis complex is simulated by neurodegeneration with brain iron accumulation. Alzheimer Dis Assoc Disord 2009;23:298-300 CrossRef Medline

13. Ehmann WD, Alauddin M, Hossain TI, et al. Brain trace elements in Pick's disease. Ann Neurol 1984;15:102-04 CrossRef Medline

14. De Reuck JL, Deramecourt V, Auger F, et al. Iron deposits in postmortem brains of patients with neurodegenerative and cerebrovascular diseases: a semi-quantitative 7.0 T magnetic resonance imaging study. Eur J Neurol 2014;21:1026-31 CrossRef Medline

15. Mackenzie IA, Neumann M, Bigio EH, et al. Nomenclature and nosology for neuropathologic subtypes of frontotemporal lobar degeneration: an update. Acta Neuropathol (Berl) 2010;119:1-4 CrossRef Medline

16. Neumann M, Rademakers R, Roeber S, et al. A new subtype of frontotemporal lobar degeneration with FUS pathology. Brain J Neurol 2009;132(pt 11):2922-31 CrossRef Medline

17. Garibotto V, Borroni B, Agosti C, et al. Subcortical and deep cortical atrophy in frontotemporal lobar degeneration. Neurobiol Aging 2011;32:875-84 CrossRef Medline

18. Feder JN, Penny DM, Irrinki A, et al. The hemochromatosis gene product complexes with the transferrin receptor and lowers its affinity for ligand binding. Proc Natl Acad Sci U S A 1998;95:1472-7 CrossRef Medline

19. Gazzina S, Premi E, Zanella I, et al. Iron in frontotemporal lobar degeneration: a new subcortical pathological pathway? Neurodegener Dis 2016;16:172-78 CrossRef Medline

20. Haacke EM, Ayaz M, Khan A, et al. Establishing a baseline phase behavior in magnetic resonance imaging to determine normal vs. abnormal iron content in the brain. J Magn Reson Imaging 2007;26: 256-64 CrossRef Medline

21. Haacke EM, Makki M, Ge Y, et al. Characterizing iron deposition in multiple sclerosis lesions using susceptibility weighted imaging. $J$ Magn Reson Imaging 2009;29:537-44 CrossRef Medline

22. Thomas B, Somasundaram S, Thamburaj K, et al. Clinical applications of susceptibility weighted MR imaging of the brain: a pictorial review. Neuroradiology 2008;50:105-16 Medline

23. Rascovsky K, Hodges JR, Knopman D, et al. Sensitivity of revised diagnostic criteria for the behavioural variant of frontotemporal dementia. Brain 2011;134:2456-77 CrossRef Medline

24. Mesulam MM. Primary progressive aphasia. Ann Neurol 2001;49: 425-32 Medline

25. Gorno-Tempini ML, Hillis AE, Weintraub S, et al. Classification of primary progressive aphasia and its variants. Neurology 2011;76: 1006-14 CrossRef Medline

26. Mathuranath PS, Cherian JP, Mathew R, et al. Mini mental state examination and the Addenbrooke's cognitive examination: effect of education and norms for a multicultural population. Neurol India 2007;55:106-10 CrossRef Medline

27. Bertoux M, O'Callaghan C, Flanagan E, et al. Fronto-striatal atrophy in behavioral variant frontotemporal dementia and Alzheimer's disease. Front Neurol 2015;6:147 CrossRef Medline

28. Nguyen T, Bertoux M, O`Callaghan C, et al. Grey and white matter brain network changes in frontotemporal dementia subtypes. Transl Neurosci 2013;4:410-18

29. Whitwell JL, Przybelski SA, Weigand SD, et al. Distinct anatomical subtypes of the behavioural variant of frontotemporal dementia: a cluster analysis study. Brain 2009;132(pt 11):2932-46 CrossRef Medline

30. Seelaar H, Rohrer JD, Pijnenburg YAL, et al. Clinical, genetic and pathological heterogeneity of frontotemporal dementia: a review. J Neurol Neurosurg Psychiatry 2011;82:476-86 CrossRef Medline

31. Duval C, Bejanin A, Piolino P, et al. Theory of mind impairments in patients with semantic dementia. Brain 2012;135(pt 1):228-41 CrossRef Medline

32. Haacke EM, Cheng NY, House MJ, et al. Imaging iron stores in the brain using magnetic resonance imaging. Magn Reson Imaging 2005; 23:1-25 CrossRef Medline

33. Rouault TA, Cooperman S. Brain iron metabolism. Semin Pediat Neurol 2006;13:142-48 CrossRef Medline

34. De Reuck J, Deramecourt V, Cordonnier C, et al. Detection of microbleeds in post-mortem brains of patients with frontotemporal lobar degeneration: a 7.0-Tesla magnetic resonance imaging study with neuropathological correlates. Eur J Neurol 2012;19:1355-60 CrossRef Medline

35. Ward RJ, Crichton RR, Taylor DL, et al. Iron and the immune system. J Neural Transm (Vienna) 2011;118:315-28 CrossRef Medline

36. Connor JR, Boeshore KL, Benkovic SA, et al. Isoforms of ferritin have a specific cellular distribution in the brain. J Neurosci Res 1994 ; 37:461-65 CrossRef Medline

37. Ridolfi E, Barone C, Scarpini E, et al. The role of the innate im mune system in Alzheimer's disease and frontotemporal lobar degeneration: an eye on microglia. Clin Dev Immunol 2013;2013: 939786 CrossRef Medline

38. Boccardi M, Sabattoli F, Laakso MP, et al. Frontotemporal dementia as a neural system disease. Neurobiol Aging 2005;26:37-44 CrossRef Medline

39. Borroni B, Brambati SM, Agosti C, et al. Evidence of white matter changes on diffusion tensor imaging in frontotemporal dementia. Arch Neurol 2007;64:246-51 CrossRef Medline

40. Agosta F, Scola E, Canu E, et al. White matter damage in frontotemporal lobar degeneration spectrum. Cereb Cortex 2012;22:2705-14 CrossRef Medline

41. Josephs KA. Frontotemporal dementia and related disorders: deciphering the enigma. Ann Neurol 2008;64:4-14 CrossRef Medline

42. Leh SE, Ptito A, Chakravarty MM, et al. Fronto-striatal connections in the human brain: a probabilistic diffusion tractography study Neurosci Lett 2007;419:113-18 CrossRef Medline

43. Nioche C, Cabanis EA, Habas C. Functional connectivity of the human red nucleus in the brain resting state at $3 \mathrm{~T}$. AJNR Am J Neuroradiol 2009;30:396-403 Medline

44. Eslinger PJ, Moore P, Antani S, et al. Apathy in frontotemporal dementia: behavioral and neuroimaging correlates. Behav Neurol 2012;25:127-36 CrossRef Medline

45. Halabi C, Halabi A, Dean DL, et al. Patterns of striatal degeneration in frontotemporal dementia. Alzheimer Dis Assoc Disord 2013;27: 74-83 CrossRef Medline

46. Macfarlane MD, Jakabek D, Walterfang $M$, et al. Striatal atrophy in the behavioural variant of frontotemporal dementia: correlation with diagnosis, negative symptoms and disease severity. PLoS One 2015;10:e129692 CrossRef Medline 